\title{
Probiotics do not significantly reduce nosocomial pneumonia
}

Luciano Silvestri ${ }^{*}$, Hendrick KF van Saene ${ }^{2}$ and Dario Gregori ${ }^{3}$

See related research by Liu et al., http://ccforum.com/content/16/3/R109

Liu and colleagues, in their recent meta-analysis, concluded that probiotics were associated with a statistically significant reduction in the incidence of nosocomial pneumonia (NP) (odds ratio $=0.75 ; 95 \%$ confidence interval $=0.57$ to $0.97, P=0.03)[1]$. These results were obtained using the fixed-effect model, ignoring a moderate level of heterogeneity $\left(I^{2}=46 \%\right)$ [2]. However, we believe that the inclusion criteria, subjects, and interventions were different among the included studies, and might have impacted the results. Good practice would therefore be to choose a more conservative analysis; that is, the random-effects model. Using this model, the claimed reduction in NP would have been not significant (odds ratio $=0.70,95 \%$ confidence interval $=0.46$ to 1.05 , $P=0.085$ ) (Figure 1). We have already addressed this issue with reference to a previous meta-analysis on probiotics $[3,4]$.

Remarkably, the authors used the random-effects model only when the $I^{2}$ test for heterogeneity was higher than $50 \%$. However, the strategy of starting with a fixed-effect model and subsequently moving to a random-effects model if the heterogeneity test is significant is discouraged by some authors [5]. The selection of a model should be based solely on the issue of which model fits the distribution of the effect sizes and takes into account the relevant sources of error.

In conclusion, this meta-analysis showed that probiotics did not significantly reduce NP. Additionally, ventilatorassociated pneumonia and mortality were not impacted. The use of probiotics to reduce these important outcomes is therefore not justified given the low level of evidence.

\footnotetext{
* Correspondence: lucianosilvestri@yahoo.it

'Department of Emergency, Unit of Anesthesia and Intensive Care, Presidio

Ospedaliero, Via Fatebenefratelli 34, 34170 Gorizia, Italy

Full list of author information is available at the end of the article
}

Silvestri and colleagues noted that a more conservative random-effects model should be used to analyze the pooled incidence of NP. The reason why we used a fixed-effect model in our analysis can be explained by the lack of statistical power. The confidence intervals tend to be wider especially when implementing a random-effects model, and the statistical significance is more likely to be lost. Regarding the potential misinterpretation among the special patient population in our review that is different from other studies $[4,6]$, we predefined heterogeneity as low, moderate or high with $I^{2}$ values above $25 \%, 50 \%$, and $75 \%$, respectively, as recommended by some authors [7]. We calculated all pooled odds ratios based on this criterion to increase the consistency of our meta-analysis.

Silvestri and colleagues are also concerned about the switch between different models. However, our population of critically ill patients, as we mentioned above, is from a heterogenetic group. Heterogeneity is an inevitable issue in studies on critical care. Using different models depending on heterogeneity [7] is supposed to be a more conservative way to interpret the results.

Despite the potential limitations of our work [1], we believe the available evidence suggests that probiotics have a marginal effect on the prevention of NP, and relevant research should not be discouraged to identify populations that benefit most from probiotics. We fully agree with Dr Silvestri and colleagues that further largescale, randomized controlled trials are warranted. This was also clearly stated in the conclusions of our metaanalysis. 


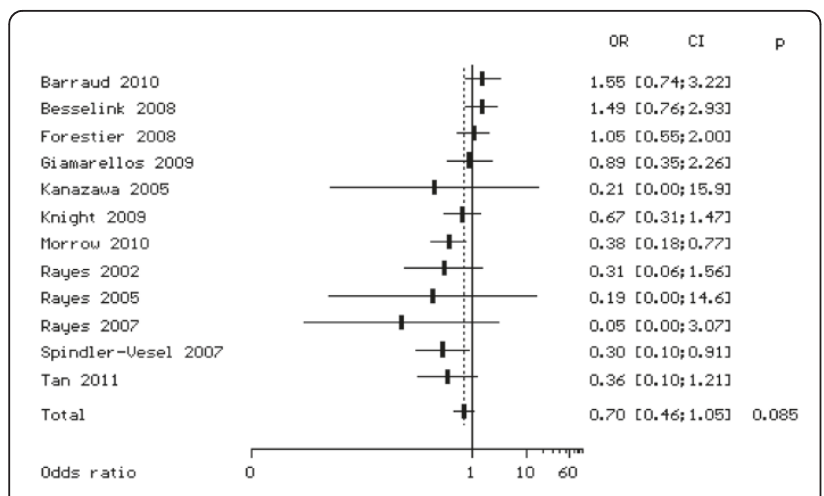

Figure 1 Forrest plot for the impact of probiotics on nosocomial pneumonia. Results presented as the odds ratio (OR) with 95\% confidence interval $(\mathrm{Cl})$ using the random-effects model. $\mathrm{OR}<1$ favors treatment; $\mathrm{OR}>1$ favors controls. Heterogeneity was not demonstrated $\left(\chi^{2}=10.4158\right.$, degrees of freedom $=11, P=0.49$; $\left.P^{2}=0 \%\right)$. The Cochran $Q$ statistic for heterogeneity was used. Heterogeneity was considered significant if $P<0.10 . P^{2}$ was evaluated with the formula $100 \% \times(Q-d f) / Q$, where $Q=$ Cochran $Q$ statistic and $d f=$ degrees of freedom (number of studies -1 ). Negative values of $P^{2}$ are set equal to $0 \% \cdot P^{2}=0 \%$, no observed heterogeneity; $P^{2}<40 \%$, mild heterogeneity; $P^{2}=30$ to $60 \%$, moderate heterogeneity; $P^{2}=50$ to $90 \%$, substantial heterogeneity; and $P^{2}=75$ to $90 \%$, considerable heterogeneity [2]. $\tau^{2}=0.20425$; heterogeneity before taking $\tau^{2}$ into consideration was moderate $\left(\chi^{2}=20.0232\right.$, degrees of freedom $\left.=11, P=0.045 ; P^{2}=45.06 \%\right)$. References to studies are included in [1].

\section{Authors' response}

Kai-xiong Liu, Ying-gang Zhu, Jing Zhang, Li-li Tao, Jae-Woo Lee, Xiao-dan Wang and Jie-ming Qu

We thank Dr Silvestri and colleagues for their interest in our meta-analysis regarding the potential effect of probiotics for the prevention of NP [1].

\section{Abbreviations}

NP: nosocomial pneumonia.

\section{Author details}

${ }^{1}$ Department of Emergency, Unit of Anesthesia and Intensive Care, Presidio Ospedaliero, Via Fatebenefratelli 34, 34170 Gorizia, Italy. ${ }^{2}$ Institute of Ageing and Chronic Disease, University of Liverpool, Liverpool L69 3GA, UK.

${ }^{3}$ Department of Cardiological, Thoracic and Vascular Sciences, Unit of Biostatistics, Epidemiology and Public Health, University of Padova, 35133 Padova, Italy.

\section{Competing interests}

The authors declare that they have no competing interests.

Received: 24 August 2012 Accepted: 1 October 2012

Published: 5 November 2012

\section{References}

1. Liu K, Zhu Y, Zhang J, Tao L, Lee J, Wang X, Qu J: Probiotics' effects on the incidence of nosocomial pneumonia in critically ill patients: a systematic review and meta-analysis. Crit Care 2012, 16:R109.

2. Higgins JPT, Green S: Cochrane Handbook for Systematic Reviews of Interventions 2011 [http://www.cochrane-handbook.org], Version 5.1.0 [updated March 2011]. The Cochrane Collaboration;.
3. Silvestri L, van Saene HKF, Gregori D, Agostini S, Francescon M, Taylor N: Probiotics to prevent ventilator-associated pneumonia: no robust evidence from randomized controlled trials. Crit Care Med 2010, 38:1616-1617.

4. Siempos II, Ntaidou TK, Falagas ME: Impact of the administration of probiotics on the incidence of ventilator-associated pneumonia: a metaanalysis of randomized controlled trials. Crit Care Med 2010, 38:954-962.

5. Borenstein M, Hedges LV, Higgins JPT, Rothstein HR: Introduction to Metaanalysis Padstow: TJ International, John Wiley \& Sons Ltd; 2009.

6. Gu WJ, Wei CY, Yin RX: Lack of efficacy of probiotics in preventing ventilator-associated pneumonia: a systematic review and meta-analysis of randomized controlled trials. Chest 2012, doi: 10.1378/chest.12-0679.

7. Higgins JP, Thompson SG, Deeks JJ, Altman DG: Measuring inconsistency in meta-analyses. BMJ 2003, 327:557-560.

\section{doi:10.1186/cc11654}

Cite this article as: Silvestri et al:: Probiotics do not significantly reduce nosocomial pneumonia. Critical Care 2012 16:453.

\section{Submit your next manuscript to BioMed Central and take full advantage of:}

- Convenient online submission

- Thorough peer review

- No space constraints or color figure charges

- Immediate publication on acceptance

- Inclusion in PubMed, CAS, Scopus and Google Scholar

- Research which is freely available for redistribution
C Biomed Central 